\title{
АУТЕНТИЧНЫЕ МАТЕРИАЛЫ НА ЗАНЯТИЯХ ПО НЕМЕЦКОМУ ЯЗЫКУ В ВУЗЕ
}

\section{AUTHENTIC MATERIALS IN THE GERMAN LANGUAGE CLASSES AT THE UNIVERSITY \\ L. Vasilenko}

Summary: The article is devoted to the analysis of the specifics of authentic materials used in German language classes at a university. The relevance of the study is due to the need to identify the most effective methods of using authentic materials in teaching a foreign language. In addition, the relevance is due to the importance of determining the role and place of these materials in the development of language skills among students in universities. The purpose of the study is to identify the features of working with authentic materials in German language classes at a university. Based on the analysis carried out, the author notes that the use of techniques for working with authentic materials depends on the communicative situation. Within the framework of this situation, the process of perceiving the material is carried out, taking into account the difficulties in understanding the texts under consideration, taking into account the age psychology of students when choosing a topic, etc.

Keywords: authentic materials; language skills; foreign language classes; modern methodological system; methods of using authentic texts.

\author{
Василенко Любовь Юрьевна \\ Дочент, Общевойсковая ордена Жукова академия \\ Вооруженных Сил Российской Федерачии \\ bag87@mail.ru
}

Аннотация: Статья посвящена анализу специфики аутентичных материалов, использующихся на занятиях по немецкому языку в вузе. Актуальность исследования обусловлена необходимостью выявления наиболее эффективных методов использования аутентичных материалов при обучении иностранному языку, а также важностью определения роли и места данных материалов в процессе развития языковых навыков у обучаемых в вузах. Цель исследования заключается в выявлении особенностей работы с аутентичными материалами на занятиях по немецкому языку в вузе. На основе проведенного анализа автором отмечается, что использование методик работы с аутентичными материалами зависит от коммуникативной ситуации, В которой осуществляется процесс восприятия информации, учета трудностей при осмыслении рассматриваемых текстов, учета возрастной психологии обучаемых при выборе тематики и т.д.

Ключевые слова: аутентичные материалы, языковые навыки, занятия по немецкому языку, современная методическая система, методы использования аутентичных текстов.

\section{I}

$\mathrm{B}$ последнее время в педагогике все большее внимание уделяется проблемам совершенствования качества обучения иностранным языкам (в т.ч. одному из основных европейских языков - немецкому), а также использования в педагогической практике различных методик на базе аутентичных материалов, которые, по мнению целого ряда ученых, способствуют улучшению практической подготовки обучаемых к устному общению на иностранном языке [2; 5]. Анализ данных проблем достаточно актуален и представляет лингвистический и педагогический интерес, обусловленный, прежде всего, необходимостью выявления наиболее эффективных методов использования такого рода материалов при обучении иностранному языку, а также важностью определения роли и места аутентичных материалов в процессе развития языковых навыков у обучаемых в вузах.

Указанные проблемы многократно исследовались отечественными и зарубежными учеными, среди них: О.Н. Игна [2], М.А. Казакова и А.А. Евтюгина [3], Н.В. Рябченко [4], Л.А. Сулимова [5], N. Demiryay [7], A. Gilmore [8], M. Itolmasov [9] и др. Однако при анализе научных источников по данной проблематике отмечается недостаточ- ное количество полных исследований, в т.ч. относительно специфики использования аутентичных материалов, что, в конечном итоге, и определило формулировку цели данной работы, которая заключается в выявлении особенностей работы с аутентичными материалами на занятиях по немецкому языку в вузе.

\section{II}

Современная система обучения иностранному языку ставит перед собой следующую задачу - передать знания таким образом, чтобы обучаемые в дальнейшем не делали ошибок при использовании языка (соответственно, язык загоняется в рамки определенных грамматических правил и форм). Однако в редких исключениях акцент делается на процессе познания, естественность которого обнаруживается именно в аутентичном материале, способном выразить мысль на уровне восприятия, состояния, образа, и обладающем «внутренней энергией слова» [3, с. 52], а также самопроизвольным и психологически мощным влиянием на обучаемых.

В процессе работы с аутентичными материалами осуществляется уникальная творческая функция человеческой психики, формируется личный языковой опыт, 
закрепляются смысловые значения объектов, предметов, явлений в сознании обучаемых [5]. Кроме того, подобная работа подразумевает акт познания и выработки определенного личностного отношения к этим предметам, объектам и явлениям: она помогает обучаемым найти свой собственный угол зрения. Однако данная научная позиция противоречит практике современного образования, поскольку «личный языковой опыт и раскрытие себя через работу с аутентичными материалами формирует определенные помехи и затруднения для педагогов» [4, с. 165], занятия которых зачастую четко структурированы и спланированы. Но все это достаточно формально, куда больший эффект был бы, если педагоги мотивировали обучаемых к занятию коллективным творчеством, предполагающим общее поле переживаний, коммуникацию обучаемых между собой на понятном для них языке.

К аутентичным материалам относятся: статьи, рекламные тексты, дневниковые записи, сказки, научные и страноведческие публикации и т.д. В рамках данной работы наибольший интерес представляют публицистические статьи из немецких журналов и газет [6], исследование которых (статей) подчеркивает важность сохранения аутентичности жанра и то, что жанрово-композиционное многообразие дает возможность обучаемым развить навык употребления в речи специфических лексических единиц, речевых клише, фразеологических оборотов и пр. С точки зрения целевой направленности аутентичных текстов, а также их использования в той или иной области их (тексты) можно классифицировать по следующим сферам общения [7, p. 242-243]:

- учебно-профессиональная (Die moderne Welt der Berufe. Das Problem der Berufswahl. Die Rolle einer Fremdsprache in der modernen Welt);

- социально-культурная (Leben in Stadt und Land. Natur und Ökologie. Jugend in der modernen Gesellschaft. Freizeit der Jugend. Wissenschaftlicher und technischer Fortschritt. Kulturelle Besonderheiten und Sehenswürdigkeiten des Landes. Reisen im In- und Ausland);

- бытовая / семейно-бытовая (Zwischenmenschliche Beziehungen. Das alltägliche Leben,

Haushaltsangelegenheiten, Familie. Verwandtschaft, Soziale Beziehungen);

- спортивно-оздоровительная (Gesundheit und Pflege für ihn. Sportarten, Sportübung).

При этом необходимо отметить, что классификация аутентичных текстов (статей) - вопрос достаточно новый: он малоизучен, к тому же теоретические основы почти не имеют систематизации, на данный момент существует лишь разрозненный материал, который требует отдельного глубокого исследования. Бесспорно лишь то, что в лингвистическом смысле аутентичные тексты определяются, во-первых, как «тексты, не предназна- ченные специально для учебных целей, но использующиеся при обучении иностранному языку», и, во-вторых, как «полученные из оригинальных источников тексты, характеризующиеся естественностью лексического наполнения и грамматических форм, ситуативной адекватностью используемых языковых средств и аутентичным словоупотреблением» [2, с. 114-116]. Из чего следует, что использование аутентичных текстов в ходе обучения иностранному языку служит имитации погружения в естественную речевую среду. Работа с аутентичными текстами приближает обучаемых к реальным условиям употребления иностранного языка, знакомит их с различными лингвистическими средствами, а также готовит к самостоятельному использованию данных средств в коммуникации.

Проблема обучения немецкому языку (с применением аутентичных текстов) требует решения целого спектра важнейших задач, среди которых: выбор методик и подходов, учитывающих все необходимые условия для восприятия и понимания иноязычного текста. При определении методик обучения также важно учитывать жанровую специфику аутентичных текстов, их функциональные и информативные особенности: функциональные особенности текстов обусловливают повседневное использование, в рамках которого реализуются инструктирующая, поясняющая, рекламирующая и предупреждающая функции; информативные особенности реализуются за счет информативной функции, которая обеспечивает постоянное появление новых сведений [9]. Также предполагается, что работа с аутентичными текстами должна сопровождаться реальной коммуникацией, которая совершается в конкретных обстоятельствах между конкретными людьми. Это в т.ч. обеспечивается за счет целого ряда требований, которым должны соответствовать аутентичные тексты, среди них:

1. Возрастные и личностные особенности обучаемых;

2. Содержание интересной информации в текстах;

3. Передача различных форм речи;

4. Наличие избыточных элементов информации;

5. Естественная форма передаваемой информации;

6. Эмоциональная составляющая информационного сообщения;

7. Наличие воспитательной ценности.

При выборе методик работы с аутентичными текстами для занятий по немецкому языку важно учитывать репрезентирующий разговорный стиль повседневного общения обучаемых. Также, необходимо, чтобы в текстах употреблялись слова и словосочетания, которые характерны для разных стилей и жанров, представив логикокомпозиционные и лексические, стилистические, семантические и пр. особенности их реализации на изучаемом иностранном языке [8, р. 103]. Кроме того, в основе выбора методик работы с аутентичными текстами должен 
лежать деятельностный подход, подразумевающий разные направления учебной деятельности:

- выяснительное (предполагает получение всей необходимой информации);

- ознакомительное (представляет собой получение познавательно-развлекательной информации);

- деятельное (характеризует подробное усваивание и запоминание информации для последующего воспроизведения).

Поскольку одна из основных целей изучения немецкого языка - подготовка обучаемых к речевому общению в естественных условиях, процесс обучения будет лишь тогда целенаправленным и эффективным, когда они (обучаемые) смогут самостоятельно преодолевать трудности, возникающие на уровне восприятия естественной речи. Роль аутентичных текстов как раз и заключается в создании иллюзии естественной речевой среды. Применение методов, в рамках которых используются аутентичные тексты, на начальном и среднем этапах обучения весьма ограничено. Как правило, это связано с наличием огромного количества лексических, грамматических и фонетических трудностей [1]. Тогда как на старшем этапе обучения немецкому языку обучаемые уже обладают достаточным запасом знаний по важнейшим языковым аспектам.

Большой эффективностью обладает метод, в рамках которого используются аутентичные тексты в тесном взаимодействии с аудированием (эффективность данного метода во многом зависит от особенностей предъявления (предоставления) аутентичного материала, количества предъявлений, объема текстовых сообщений, принципов полезной избыточности, опоры и ориентиров восприятия и пр.) [4, с. 165]. Среди факторов, способствующих более успешной реализации метода на занятиях по немецкому языку в вузе, следует выделить: объективные факторы (зависят от обучаемых, условий восприятия и лингвистических особенностей - языковых и структурно-композиционных сложностей текстовых сообщений) и субъективные факторы (подразумевают наличие у обучаемых потребностей в знаниях и интереса к теме сообщения).

В качестве примера приведем ряд упражнений, который предлагается выполнить обучаемым после предварительного прослушивания публицистического текста «Warum auch Geimpfte das Virus verbreiten könnten» L. Fischer, опубликованного в журнале «Spektrum» [6]:

1. Уточните значение данных лексических единиц по словарю: Schlupflöcher; neutralisierender Antikörper; die Immunreaktion; einen Schutzschild; beim Gelbfieber; Denguefieber; der Impfstoffcocktail.

2. Составьте пары антонимов: modern; krank; eckig; offen; breit; verschlossen; alt; schnell; weit; rund; langsam; schmal; eng; gesund.
3. Вставьте в предложения следующие слова и выражения: eine sterile Immunität; die mukosale Immunantwort; einen Schutzschild; die Infektion zu verhindern; die erste Impfdosis.

a) Die mukosale Impfung sei sehr interessant, wenn es darum geht, nicht nur die Krankheit, sondern auch ..., sagt Riese.

b) Ob auch ... ausreichend ist, damit Geimpfte nach einer Infektion gar nicht mehr oder zumindest weniger ansteckend sind, untersuchen Fachleute derzeit in Studien.

c) Untersuchungen der Krankenkassen in Israel deuten laut Riese immerhin darauf hin, dass ... auch die Übertragung des Virus um 30 bis 50 Prozent reduziere.

d) Für ... braucht man entweder eine große Menge neutralisierender Antikörper oder effektive zytotoxische T-Zellen im Blut.

e) Geimpfte würden dann weiterhin andere Menschen anstecken, statt ... zu bilden.

4. Переведите с немецкого языка на русский:

a) Doch dass die aktuellen Coronavirus-Impfstoffe diese Aufgabe gut erfüllen, ist keine Garantie, dass eine sterile Immunität ebenfalls häufig ist.

b) Außerdem verändern sie sich dauernd, so dass der Impfstoffcocktail nicht alle kursierenden Viren optimal abdeckt.

c) Zwar zeigen Studien, dass auch die Impfungen eine sehr gute Antikörperantwort erzeugen - doch das ist bisher nur für das im Blut zirkulierende Immunglobulin G nachgewiesen.

После выполнения этих и других подобных упражнений обучаемым может быть предложен к прочтению текст данной статьи, затем также предложен ряд упражнений, в рамках которых текст статьи переводится, комментируются отдельные слова, фразы и выражения. Упражнения могут быть следующего характера:

1. Верны ли утверждения?

a) Ob bei einer bestimmten Impfung beides gelinge, hänge von drei Punkten ab: Der Art des Erregers, um was für einen Impfstoff es sich handelt und wie der Erreger übertragen wird.

b) Ein Geimpfter müsste vielleicht jeden fünf Tag getestet werden, um festzustellen, ob er sich möglicherweise infiziert hat.

2. Ответьте на вопросы:

a) Was ist die Hauptidee des Artikels?

b) Stimmen Sie den Aussagen des Autors zu?

c) Was sind die Hauptprobleme, die im Text behandelt werden?

d) Ist der Autor damit einverstanden, dass die Impfung die Pandemie verlangsamt?

e) Sind Nasensprays bei der Behandlung von Coronaviren wirksam?

3. Подготовьте план и сделайте краткий пересказ на русском / немецком языках, и т.д. 
Отдельно следует упомянуть так называемый метод обучения в парах / группах, где, в частности, может осуществляться работа с различными аутентичными текстами (тексты могут быть разными по жанру, стилю или, напротив, одинаковыми, для выявления особенностей текстовой формы). В рамках данной работы могут решаться вопросы общего смысла текста, отдельных аспектов содержания, дискурсивных моментов перевода и пр. Кроме того, возможен метод творческого представления аутентичного текста, с целью создания последующего интерактива, включающего аудиторию в смысловое, эмоциональное текстовое пространство [3, с. 53]. Однако подобная форма в большей степени подходит для работы с художественными текстами (с публицистическими, научными, историческими источниками, документами более подойдут индивидуальные формы обучения, позволяющие глубоко погружаться в материал).

Так, в качестве примера могут быть приведены парные / групповые упражнения, составленные на базе аутентичного текста «Vom Schließen und Öffnen der Ohren» A. Maier (текст опубликован в журнале «Psychologie heute») [6]. В частности, после прочтения данного текста обучаемым предлагается выполнить следующее:

1. Одному из обучаемых самостоятельно составить вопросы по содержанию текста, другому / другим развернуто ответить на них.

2. Каждому в паре / группе раздать карточки, например, со следующими заданиями:

a) Sätze kombinieren:

- Ich kann mir die damalige Welt nicht anders ausmalen als eine farbige Fläche, die ins DiffusEinheitliche neigte...

- Fest eingebrannt haben sich zwei gleichbleibende Geräusche, die einfach ...

- Meine ersten Erinnerungen haben mit Lauten nichts zu tun, auch wenn ich die Stimme meiner Urgroßmutter, die mich meistens bei sich hatte, oder meiner Mutter...

***

... und der anderen natürlich gehört und mit Sicherheit auch darauf reagiert haben muss.

... und gut wiedererkennbar waren und sich über Jahre nie änderten.

... und die mir nicht als Objekt gegenüberstand, sondern in der ich aufging.

b) Stimmen Sie dem Ausdruck zu?

- Zum einen handelte es sich um das Gurren von Tauben (ich liege und das Fenster ist geöffnet), zum anderen um die Glocken der nahegelegenen Dankeskirche.

- Sind letzte Erinnerungen rein optischer Natur, nämlich eben die Enten im Bad Nauheimer Kurpark. Und Herbstlaub.

3. Каждому предложить составить план текста и в тезисной форме пересказать его, при этом обсуждая в паре / группе основную идею текста, его лексические и стилистические особенности, и т.д.

Кроме того, использование методик работы с аутентичными текстами на занятиях по немецкому языку в вузе во многом зависит от коммуникативной ситуации, в которой осуществляется процесс восприятия материала, учета трудностей при осмыслении рассматриваемых текстов, учета возрастной психологии обучаемых при выборе тематики и т.д. Разработка учебного процесса, четкость и логичность изложения аутентичных текстов, опора на активную мыслительную деятельность, многообразие приемов обучения - все это позволяет развивать внутреннюю мотивацию обучаемых, направить их внимание на процессы восприятия и познания аутентичного материала. Формируемый при этом эффект участия в повседневной жизни страны осваиваемого языка с ее особой культурой не только содействует обучению естественному, живому языку, но и служит сильнейшим стимулом для развития человека.

\section{III}

Таким образом, рассмотрев особенности работы с аутентичными материалами на занятиях по немецкому языку в вузе, можно сделать вывод, что в процессе изучения языка целесообразно соблюдать принцип поэтапности, который позволит сформировать навыки и умения работы с аутентичными текстами. На занятиях следует обращать особое внимание на социокультурный фон рассматриваемых тем, содержание и смысл текстов, а также имплицитность речи (на то, что кроется за словами: на что в тексте есть только намеки, а не прямые указания). Все это будет способствовать успешному формированию лексических, грамматических и фонологических навыков работы с аутентичными материалами за счет снятия различного рода языковых трудностей.

Педагогический процесс следует выстраивать таким образом, чтобы обучаемые стремились воспринимать аутентичные тексты, в т.ч. в контексте межкультурной коммуникации, а для этого нужно обеспечить их фоновыми знаниями. Мотивированность обучаемых заниматься коллективным творчеством в ходе использования методик работы с аутентичными текстами на занятиях по немецкому языку формирует общее коммуникативное пространство, где осуществляется общение обучаемых между собой на понятном для них языке, а также взаимодействие педагога и обучаемых, в едином поле целостного реально-идеального пространства духовной и духовно-практической культуры [7]. В целях формирования и развития данного пространства должна быть разработана целостная современная методическая система, учитывающая все трудности изучения немецкого языка в вузе и способствующая их преодолению. 


\section{ЛИТЕРАТУРА}

1. Ершова Н.Б. Специфика языка немецкой прессы / Н.Б. Ершова, 0.А. Левковская // Филологические науки. Вопросы теории и практики. Вып. 4(70) в 2-х ч. Ч.2. Тамбов: 000 «Грамота», 2017. С. 99-102.

2. Игна 0.Н. Развитие социокультурной компетенции студентов на основе аутентичных материалов при профессионально-ориентированном обучении иноязычному общению: немецкий язык, технический вуз: дис. ... канд. педагог. наук: 13.00.02 / 0.Н. Игна. Томск: Тамб. гос. ун-т им. Г. Р. Державина, 2003. $256 \mathrm{c}$.

3. Казакова М.А. Аутентичные текстовые материалы в обучении иностранному языку / М.А. Казакова, А.А. Евтюгина // Вестник бурятского государственного университета. Образование, личность, общество. 2016. № 4. С. 50-58.

4. Рябченко Н.В. Особенности аутентичных текстов современной немецкой прессы (при обучении немецкому как иностранному) / Н.В. Рябченко // Современное педагогическое образование. 2019. № 5. С. 164-166.

5. Сулимова Л.А. Использование аутентичных материалов на разных этапах обучения иностранному (немецкому) языку / Л.А. Сулимова // Педагогическое мастерство: матер. V Междунар. науч. конф. (г. Москва, ноябрь 2014 г.). М.: Буки-Веди, 2014. С. 19-22.

6. Топ-10 аутентичных немецких журналов // Читаем на немецком: LF: lingua franconia [Электронный ресурс]. Режим доступа: https://linguafranconia.com/ deutschemagazine (дата обращения 22.01.2021).

7. Demiryay N. Authentische Materialien aus der Perspektive von Fremdsprachendidaktik: Überlegungen zur Anwendbarkeit / N. Demiryay // ZfWT. 2016. Vol.8; No. 1. Pp. 239-253

8. Gilmor, A. Authentic materials and authenticity in foreign language learning / A. Gilmore // Language Teaching. 2007. No. 40. Pp. 97-118.

9. Itolmasov M. The role of authentic materials in foreign language teaching / M. Itolmasov // Проблемы педагогики. 2019. № 4(43). С. 19-20.

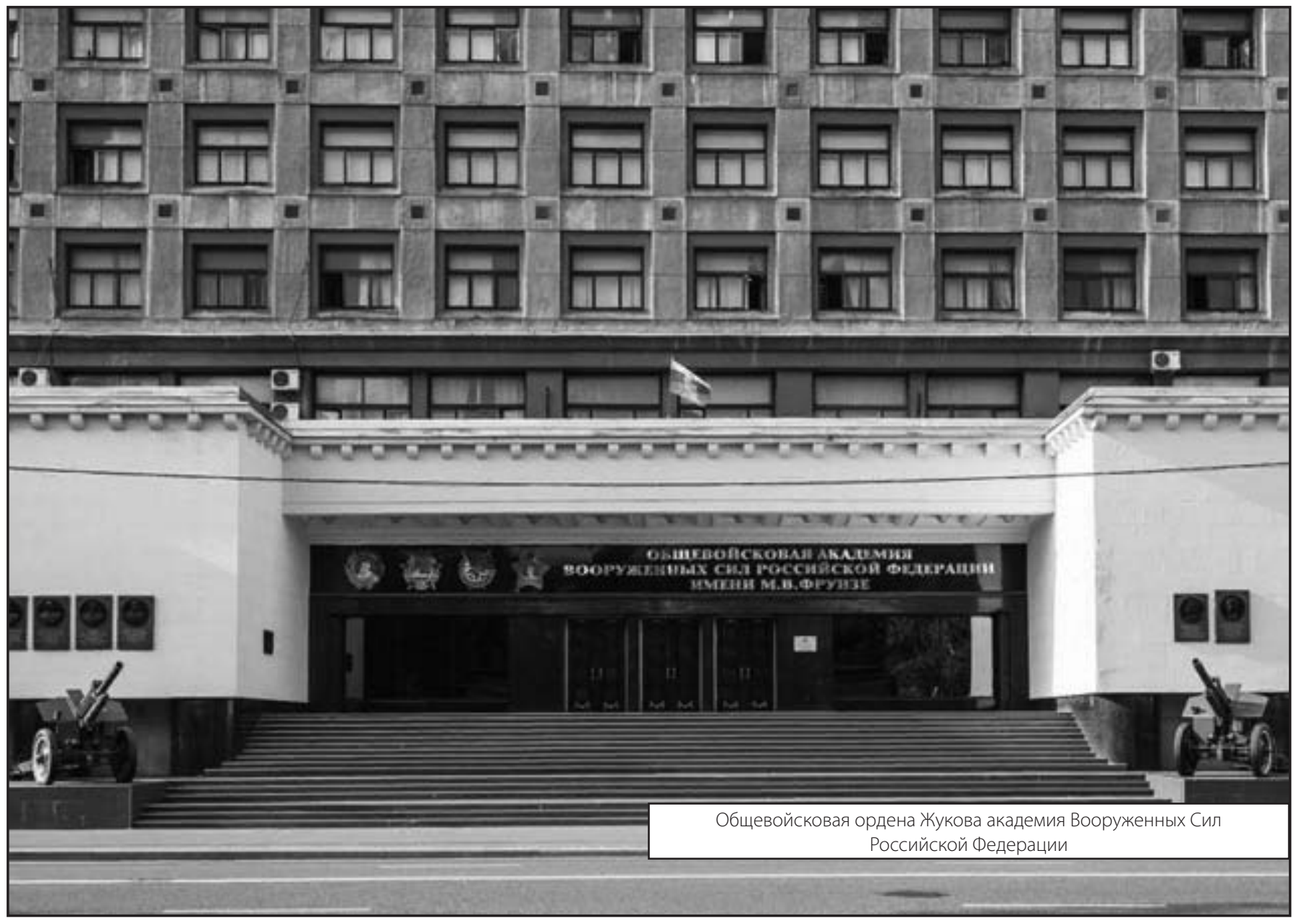

